\begin{tabular}{|l|l|l||}
\hline \multicolumn{2}{|c|}{ PublisherInfo } \\
\hline \hline PublisherName & $:$ & BioMed Central \\
\hline \hline PublisherLocation & $:$ & London \\
\hline \hline PublisherImprintName & $:$ & BioMed Central \\
\hline \hline
\end{tabular}

\title{
Mice tolerate siRNAs
}

\begin{tabular}{|l|l|l||}
\hline \multicolumn{2}{|c|}{ ArticleInfo } \\
\hline \hline ArticleID & $:$ & 5018 \\
\hline \hline ArticleDOI & $:$ & $10.1186 /$ gb-spotlight-20041125-01 \\
\hline \hline ArticleCitationID & $:$ & spotlight-20041125-01 \\
\hline \hline ArticleSequenceNumber & $:$ & 81 \\
\hline \hline ArticleCategory & $:$ & Research news \\
\hline ArticleFirstPage & $:$ & 1 \\
\hline \hline ArticleLastPage & $:$ & 3 \\
\hline \hline & & RegistrationDate : 2004-11-25 \\
ArticleHistory & $:$ & OnlineDate $\quad$ 2004-11-25 \\
\hline \hline ArticleCopyright & $:$ & BioMed Central Ltd2004 \\
\hline \hline ArticleGrants & $:$ & \\
\hline \hline ArticleContext & $:$ & 130595511 \\
\hline \hline
\end{tabular}


Small interfering RNAs (siRNAs) can be used to silence genes in mice without triggering an immune response, a report appearing online November 21 from Nature Biotechnology reveals (Nat Biotechnol 2004, DOI:10.1038/nbt1038).

"There have been discussions based on cellular studies that suggest immune responses may occur," senior author Mark Davis of the California Institute of Technology in Pasadena told us. "What is exciting is that siRNAs were well tolerated in animals."

Recent in vitro studies revealed siRNAs could activate the interferon system, raising concerns they might have toxic effects that would limit their potential as therapeutics. "These experiments really needed to be taken to the animal level," said John Rossi of the Beckman Research Institute of the City of Hope in Duarte, Calif., who did not participate in this study.

Davis and colleagues gave mice naked synthetic siRNAs against fatty acid synthase (FAS), c-MYC, or luciferase, either through intraperitoneal injections or via the tail vein using either low-pressure (1\% volume/weight) or high-pressure (10\% volume/weight) methods. "Different injection methods can lead to different concentrations of material in various organs," Davis explained.

Enzyme-linked immunosorbent assay (ELISA) showed that siRNA failed to trigger a strong type I interferon alpha response regardless of which siRNA was injected or the injection method. In comparison, injections of polyinosinic acid:polycytidylic acid [poly(I:C)] - an analog of long double stranded RNA - triggered strong interferon responses.

The researchers also monitored what effect siRNAs had on a marker for Toll-like receptors 3 and 9 (TLR3 and TLR9), which are speculated to recognize siRNA and trigger interferon upregulation. Both receptors' intracellular signal transduction pathways promote transcription of cytokines such as interleukin-12. ELISA analysis showed that while poly(I:C) - which TLR3 recognizes - triggered a strong interleukin-12 response, the siRNAs did not.

To confirm that siRNAs reached an intracellular target and functioned in a sequence-specific manner, the researchers injected mice with plasmids containing the luciferase gene and siRNA against either luciferase or an unrelated sequence. Live whole-animal imaging showed that mice co-injected with the luciferase-targeting siRNA displayed a significant downregulation of luciferase expression in the liver that was not observed with the control siRNA.

High-pressure tail vein injection of siRNA against FAS also reduced the level of FAS mRNA in mouse liver. This downregulation was not seen with low-pressure tail vein injection of the same siRNA at the same dose, consistent with prior observations that high pressure is required to downregulate a gene with siRNA in the livers of mice, even if the siRNA is chemically stabilized.

"No interferon response and no inflammatory response, nothing but knocking down the gene in the target. It bodes well for using siRNAs therapeutically," Rossi told us. 
John Taylorof the Fox Chase Cancer Center in Philadelphia, who did not participate in this study, was encouraged that the researchers did not find any interferon response. "But one still has the issue of how much of a response they could have measured," he told us. "For many people applying siRNA strategies to use in patients, even small interferon responses could become a major issue, as are off-target results, when seeking approval from regulatory agencies. One has to be careful how detectable they are."

To reconcile their results with prior cell culture findings, Davis and colleagues suggested investigating any influence that cell type, intracellular trafficking, siRNA concentration, method of siRNA preparation, and siRNA sequence had on immune response. For instance, Davis said his team is moving from naked nucleic acids to non-viral delivery systems.

Past studies in cultured cells found interferon response from expressed siRNAs using lipid vectors. "It may be that lipid release delivery in itself causes some sort of stress reaction," Rossi added. "And it could turn out some sequences have some motif in them that might turn out to be immunogenic."

\section{References}

1. Nature Biotechnology, [http://www.nature.com/nbt/]

2. Mark E. Davis, [http://www.che.caltech.edu/faculty/davis_m/]

3. Lucenti J: Silencing cancer The Scientist, September 13, 2004., [http:/www.the-scientist.com/ yr2004/sep/feature_040913.html]

4. John J. Rossi, [http://www.cityofhope.org/gradschool/faculty/jrossi.asp]

5. Pallarito K: Fuelling the fires of RNA interference The Scientist, September 13, 2004., [http://www.the-scientist.com/yr2004/sep/feature2_040913.html]

6. John M. Taylor, [http://www.fccc.edu/research/pid/taylor]

7. Johnston N: Seeds of a micro revolution The Scientist, September 13, 2004., [http://www.thescientist.com/yr2004/sep/feature1_040913.html] 